\title{
Some Abnormal Fishes Received at the Plymouth Laboratory.
}

\author{
By
}

E. Ford, A.R.C.Sc.,

Fisheries Naturalist at the Plymouth Laboratory.

With 8 Figures in the Text, and Plates I-V.

\section{INTRODUCTION.}

THE object of this short paper is to describe a number of fishes exhibiting interesting abnormalities. It will be seen from the list given below that several of the specimens to be described were sent to the Laboratory on the personal initiative of gentlemen to whom I express my thanks. I am also greatly indebted to Dr. H. A. Harris and the staff of the X-ray Department of the Institute of Anatomy, University College, London, for the beautiful radiograms they supplied. Mr. C. H. Gill, Press Photographer, of Plymouth, photographed several specimens and also prepared prints for the illustrations.

List of Spectmens DESCRIBED.

1. Cod with Malformed Mouth*

2. A Pug-headed Herring

3. A Fan-tailed Pilchard

4. Coalescence of Vertebræ in a Lemon-Dab (Pleuronectes microcephalus Donov.)

5. A Deformed Stickleback (Spinachia vulgaris Flem.)

6. Abnormal Rays
6 A Raia microcellata Mont.
6 B Raia clavata L.
Jan. 1st, 1928
Feb. 24th, 1930

6 C Raia microcellata Mont.

6 D Raia microcellata Mont.

7. Double-monster of the SpurDogfish (Acanthias vulgaris Fisso)

* I am indebted to Dr. R. H. Burne, F.R.S., and the Pathologist at the Royal College of Surgeons for their report on this specimen, and for the half-section of the fish figured in Plate $\mathrm{I}$.
Date

Received.

May 10th, 1929

April 5th, 1929

June 14th, 1928

Feb. 25th, 1930

Feb. 25th, 1930

Aug. 9th, 1929

July 11th, 1927

Oct. 9 th, 1928 


\section{A Cod with Malformed Mouth.}

The cod showing this abnormality measured $86.5 \mathrm{~cm}$. in length and was in fairly good bodily condition despite its seemingly serious disability. The external features of the head are well shown in Text-Figs. 1 and 2. The snout projects beyond a curiously deformed lower jaw with a bulbous growth beneath, giving the head a most quaint appearance. The barbel (b), normally central, lies to the right of the bulbous growth, and what would normally be the left half of the lower jaw $(d)$ is symmetrically arched across and beneath the upper jaw, presumably functioning as a

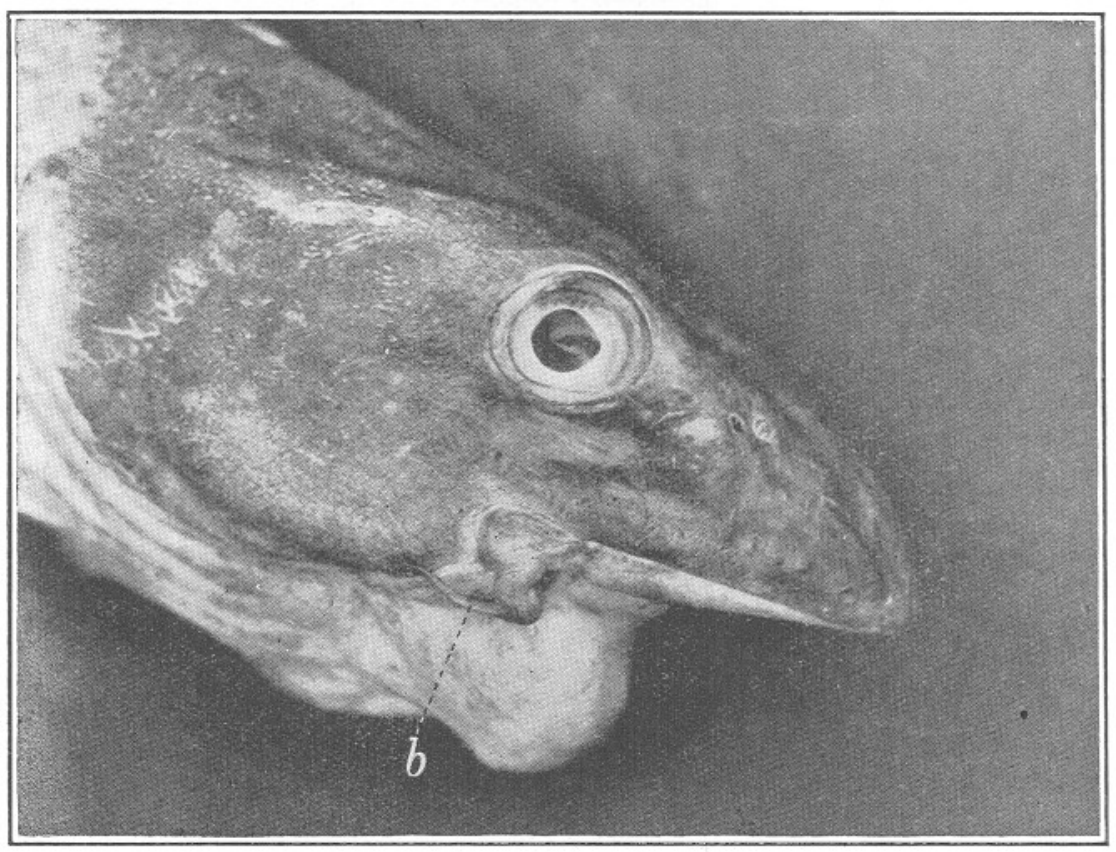

Texт Fig. 1.-Head of Malformed Cod, viewed from right side. (Photo, C. H. Gill.)

whole lower jaw. The representative of the right half of the lower jaw is displaced and doubled back upon itself at a sharp angle with the left half. When first observed, the bulbous growth was ulcerated (Text-Fig. 2.a), leading one to suspect that it was pathological in character. The specimen was later sent to the Royal College of Surgeons where sagittal sectioning revealed the true state of affairs. Plate I from a photograph of the cut face of the left half of the head serves to illustrate the conclusions communicated to me by Dr. Burne. The protuberance is not a tumour, but is due to the downward bending of the tongue (Plate $\mathrm{I}, t$ ), pushing the 
intermandibular wall before it. Dr. Burne suggests that the condition is a congenital one; i.e. want of growth of the lower jaw accompanied by full growth of the tongue, and the necessity for the tongue to find room. Instead of growing out of the mouth, the tongue has bent downwards, pushing the sub-mental wall before it. It occurs to me to suggest that the process described by Dr. Burne might have produced the end result if it came into operation subsequent to an injury to the lower jaw of a

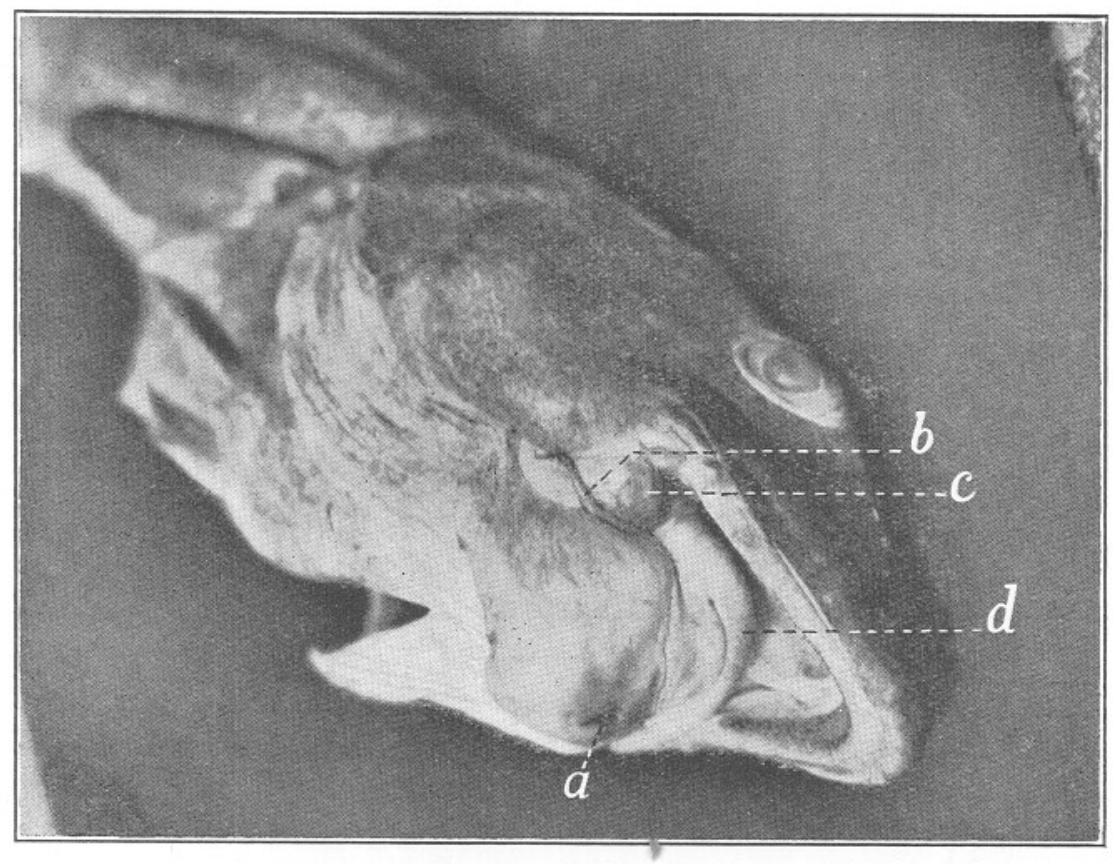

Text Fig. 2.-Head of Malformed Cod, viewed obliquely from beneath. (Photo, C. H. Gill.)
a. lesion on ventral protuberance.
b. barbel, normally median in position.
c. original right-half of lower jaw.
d. original left-half of lower jaw, now functioning as whole lower jaw.

young normal individual. This fish certainly provides an excellent illustration of the ability to survive and grow under adverse circumstances.

\section{A Pug-headed Herring.**}

This specimen, $8 \mathrm{~cm}$. in length, exhibits the features described by Gemmill (2, p. 48) and others under the name of "pug-head." Of this

* Dr. E. W. Gudger has recently published an interesting paper entitled "PugHeadedness .in the Striped Sea-Bass, Roccus lineatus, and in Other Related Fishes." Bull. Amer. Mus. Nat. Hist., Vol. LXI, March 31, 1930. 
condition Gemmill says: "In typical examples the snout is markedly reduced in size, and curved in such a way that the anterior frontal region arches rapidly downwards just in front of the eyes. The latter are lessened in horizontal diameter and become oval in shape, having the long axis vertical. The lower jaw retains its usual size, and accordingly projects a considerable distance in front of the rest of the head." It can be seen from Text-Fig. 3 that the specimen conforms with this type description. In other respects the fish was normal and in healthy condition, its stomach being well-filled with recently-caught mysids. Gemmill refers to the interesting results of Knauthe who allowed breeding between males and females of Leucaspius delineatus v. Sieb. and Cyprinus aphya?, which, though apparently normal, were derived from " puggy"

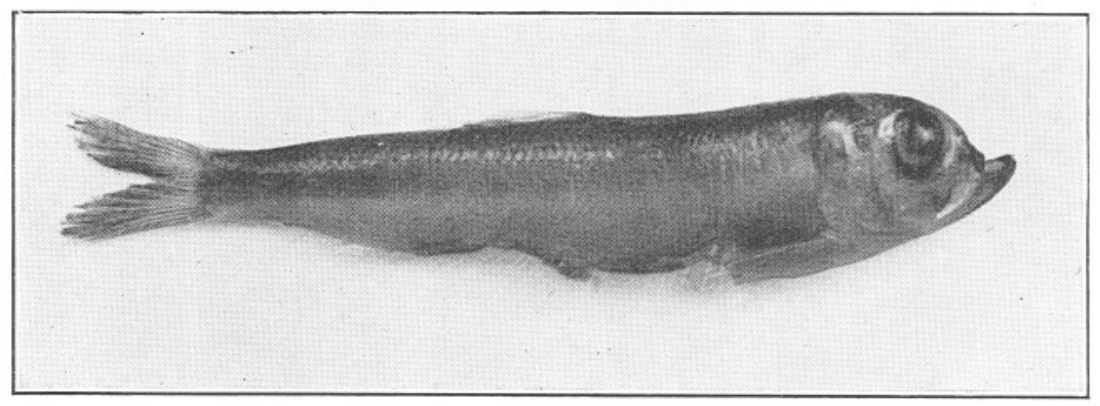

Texr Fig. 3.-A Pug-headed Herring. Length $8 \mathrm{~cm}$.

parents or grandparents. For instance, he found that a male and female Leucaspius, normal themselves though derived from "puggy" parents, provided in the offspring the large number of 50 out of 180 which "reverted" to the grandparental form. In later experiments with Cyprinus he was able to show that 6 of a total of $1 € 8$ progeny were "puggy" like their great-great-grandparents although the intervening ancestors were all apparently normal.

\section{A Fan-tailed Pilchard.}

Measurements of this unusual specimen resulted as follows :-

Tip of snout to root of tail . . . $20 \cdot 8 \mathrm{~cm}$.

Tip of snout to end of mid-caudal ray . $22 \cdot 0 \mathrm{~cm}$.

Tip of snout to end of flukes . . $26 \cdot 6 \mathrm{~cm}$.

Greatest width of tail across flukes $\quad 6 \cdot 5 \mathrm{~cm}$.

The relative size of the tail as compared with that of a normal fish of approximately the same length may be gathered from Plate II. Photography by X-rays (Plate II) reveals that the leaf-like expansion of the 
tail is due to an excessive lateral branching and rebranching of the dermal fin-rays. At their proximal ends the latter retain their rod-like appearance and are in normal association with the endoskeletal elements of the caudal fin.

\section{Coalescence of Vertebra in a Lemon-Dab (Pleuronectes microcephalus Donov.)}

The small Lemon-Dab in which this abnormality was observed measured $22.5 \mathrm{~cm}$. from the tip of the snout to the end of the middle rays

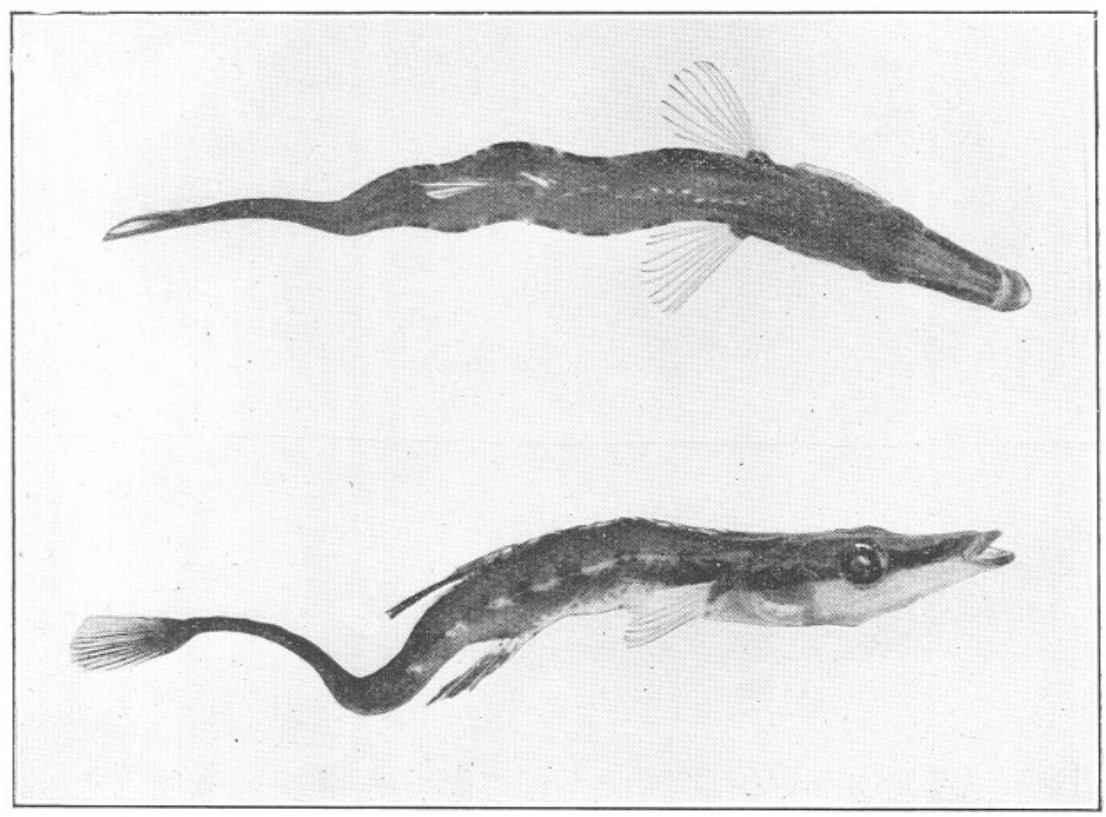

Text FIG. 4.-A Deformed Stickleback (Spinachia vulgaris Flem.).

Upper: From above. Lower: From side.

of the caudal fin. It will be seen from the X-ray photograph (Plate III) that as the result of considerable co-ossification of vertebræ in the posterior half of the vertebral column the fish presents the contour of a top-knot rather than of a lemon-dab at the tail-end. The outer edge of the caudal peduncle is thus brought almost into alignment with the bases of the dorsal and anal fins in this region. Photography by $\mathrm{X}$-rays has conveniently revealed the main features of this vertebral abnormality. Anteriorally the vertebræ appear to be normal and it is not until about the 18th vertebræ from the front that anything markedly unusual is 
noticeable. At this point, however, there are signs of a dorso-lateral displacement of vertebræ, particularly evident in the next half a dozen vertebræ. It is as if these had become forced out of alignment as the result of undue compression along the vertebral column. Behind these obviously displaced vertebræ, the remainder of the series appear to be

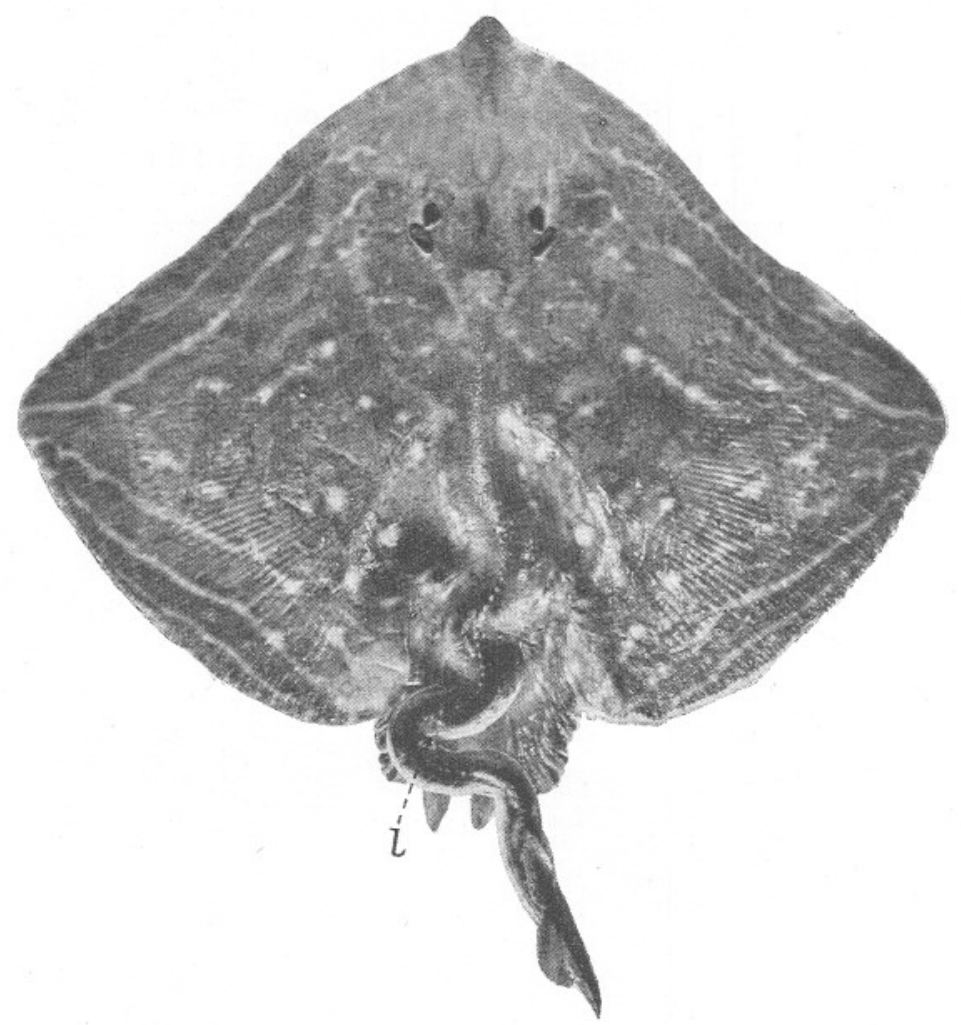

Text Frg. 5.-Abnormal Raia microcellata Mont. Specimen $6 \mathrm{C}$, described in text.

co-ossified to form several unequal-sized blocks of fused vertebræ. Continuing the use of the "compression" analogy the appearance is as if pressure had been here so great that the centra had been forced to collapse together like the bellows of a camera, rather than being displaced dorso-ventrally. Nevertheless, the identity of the vertebræ still remains apparent in that the neural and hæmal spines are properly paired and normal in number, representing a total of 47 (or 48 ?) vertebræ exclusive of the caudal end-piece. 


\section{A Deformed Sea-Stickleback (Spinachia vulgaris Flem.)}

This little fish of $8 \mathrm{~cm}$. in length was alive and active when brought to the Laboratory and presented a most odd appearance while swimming in an aquarium. Viewed from the side (TextFig. 4) it showed a marked kink in the tail region posterior to the dorsal fin. Seen from above, it exhibited a sinuous formation of the body. Photographs by X-rays show that the vertebral column follows the lines of the kink and waves of the body but that the vertebræ are normal in character. This instance adds another to the long list of references given by Gemmill $(\boldsymbol{2}$, p. 52$)$ to cases of twisted bodies with or without associated coalescence of vertebræ. Gemmill refers to examples of twisting or curvature without coalescence of vertebræ (i.e. of the class to which the present stickleback belongs) in a sole and in a codfish, described by Howes (4) and Storrow $(6)$ respectively. In both there were five sinuosities.

\section{Abnormal Rays.}

6 A. A small female of Raia microcellata Mont., measuring $26 \mathrm{~cm}$. across the disc, was found to show fin abnormalities on the right side. The pectoral was separated from the head by a deep triangular notch involving two gill-clefts. The posterior lobe of the right ventral fin was also divided into two by a somewhat shallower notch. These features are shown in Plate IV, $6 \mathrm{~A}$.

6 B. A mature male of Raia clavata L., measuring $51 \mathrm{~cm}$. across the disc, had the

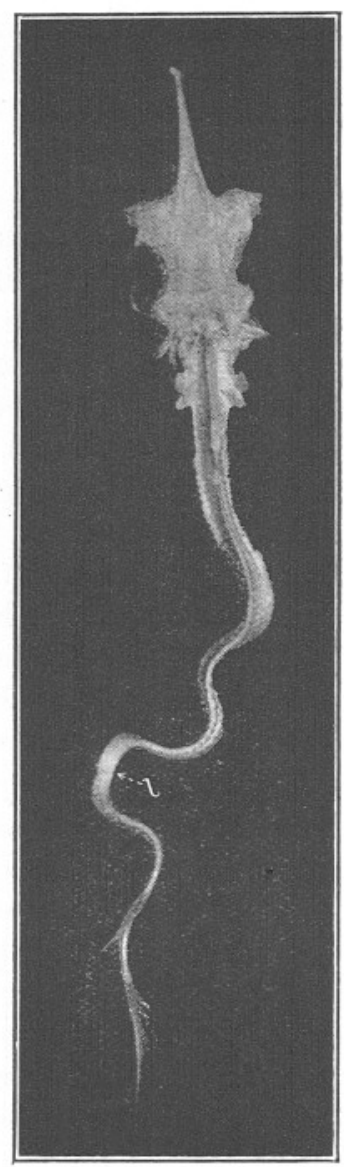

Text Fig. 6.

Vertebral skeleton of specimen $6 \mathrm{C}$, described in text. pectorals of both right and left sides separated from the head (Plate IV, 6 B), although in this case the separation did not extend so far back as in specimen $6 \mathrm{~A}$, nor was there any accompanying abnormality of the ventral fin.

There are numerous references in literature to rays in which the pectoral fins are not adherent to the head, more commonly, perhaps, to cases in which both fins are free as in specimen 6 B. Bashford Dean (1, p. 620) 
cites the genera Hieroptera and Propterygia as being originally described as specific forms although now known to be rays of this peculiarly abnormal type. He also credits Gesner (3) with the first known account and figure in 1556, and gives a list of references to published accounts in later times. Williamson (8, p. 64) advances reasons against the explanation of these abnormalities as the result of cuvting by fishermen, pointing out the exactitude of the separation along the dividing-line between the snout and the fin on either side. Johnstone (5, p. 188) suggests that the malformation is due to the assumption, during development, by the propterygia, of a position which is more nearly related to the primitive position of the Elasmobranch pectoral fin-structures than the latter normally occupy in skates and rays. The fact that in specimen $6 \mathrm{~A}$ the posterior lobe of the ventral fin is also bifurcated adds interest to the question of the causation of such abnormalities in rays.

$6 \mathrm{C}$ and $6 \mathrm{D}$. By an odd coincidence two male rays of the same species (R. microcellata Mont.), taken in the same haul of the otter trawl,* showed sinuous twisting of the vertebral column.

6C. This specimen measures $49 \mathrm{~cm}$. across the disc, and the very abnormal condition of the tail is apparent from Text-Fig. 5 reproduced from a photograph. The appearance of the vertebral column (prepared by boiling and cleaning away the flesh) is shown in Text-Fig. 6. Attention is drawn especially to the pronounced " elbow " at $(l)$, where in addition to the action of a wave of lateral displacement there is marked tortion in a clockwise direction through an angle of almost $90^{\circ}$. This twisting is, however, quite local to loop $(l)$, the tail posteriorally retaining its normal dorso-ventral position although, of course, exhibiting the laterallysinuous condition. The "elbow" at $(l)$ was quite flexible, so that one imagines that the fish when alive could freely swing the tail posterior to it.

$6 \mathrm{D}$. The second specimen, not figured here, was $48 \mathrm{~cm}$. across the disc and more normal in appearance. The vertebral column was quite normal from the head backwards to the level of the distal ends of the ventral fins, but at this point there was one well-marked lateral looping, followed by a second in the region of the dorsal fins. There was nothing comparable to the tortion shown in specimen $6 \mathrm{~B}$, nor, one thinks, was the fish unduly affected in its tail-action during life.

\section{Double Monster of the Spur-Dogfish (Acanthias vulgaris Risso.)}

This specimen was first noticed among the embryos in the offal from dogfish being prepared for market at Newlyn. It was forwarded to

\footnotetext{
* My colleague, Mr. G. A. Steven, was aboard the Salpa on this occasion and brought back the specimens.
} 
Plymouth in methylated spirit, curled up in a rather small bottle, and apart from the lack of the yolk-sac was entire.

\section{External Features.}

In size and development the monster may be likened to the union of two embryos between 13 and $15 \mathrm{~cm}$. in length which had grown at the expense of not much more than one-half of the original supply of yolk. The two members lie with their ventral surfaces in apposition, and they are united from the level of the yolk-stalk backwards to the tail. The union is thus one of Gemmill's Class VI (2, p. 21). The larger member (A), in Plate $\mathrm{V}$, appears normally developed with respect to the head,

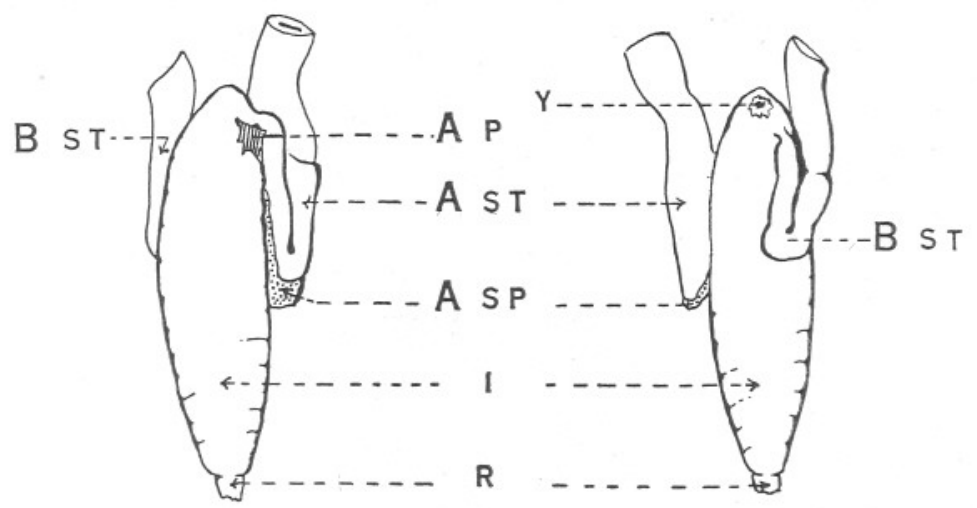

Text Fig. 7.-Gut of Double-monster of Acanthias vulgaris Risso.

A. ST. Stomach of larger member A.

A. SP. Spleen of larger member A.

A. P. Pancreas of larger member A.

B. sT. Stomach of smaller member B.

I. Intestine.

R. Rectum.

Y. Opening of internal yolk-sac into intestine.

pectorals and two dorsal fins; the smaller member (B) also exhibits normal gills, pectorals and dorsals, while the head is typical save for malformed nostrils. The no trils in (A) are quite normally separated laterally by an appreciable interval, whereas in (B) they are adjacent and lie in a shallow pear-shaped depression (Plate $\mathrm{V}(n)$ ). The general pigmentation in both members is normal and most effectively indicates the identity of each. There is but one pair of pelvic fins (female in structure) situated on the left side as the monster is viewed with the larger member uppermost. On this same side a groove occupies the middle line from the anus backwards towards the tail. Still viewing the specimen with member (A) uppermost, it is seen that the body of the latter passes by a rather abrupt downward kink about $1 \mathrm{~cm}$. behind the 
second dorsal fin into an almost normal heterocercal tail. Tracing the smaller member (B) backwards it would seem to possess no tail, the body stopping short somewhat suddenly to fuse with that of (A) at the level of the kink. At the root of the single well-formed tail, however, there is a small fleshy lobe, (c) in Plate V, left, which may represent the tail of (B).

Digestive System.

The digestive organs of the specimen presented an interesting condition which is, perhaps, most conveniently described by starting from the single short rectum (Text-Fig. 7, R) and working forward. The rectum,

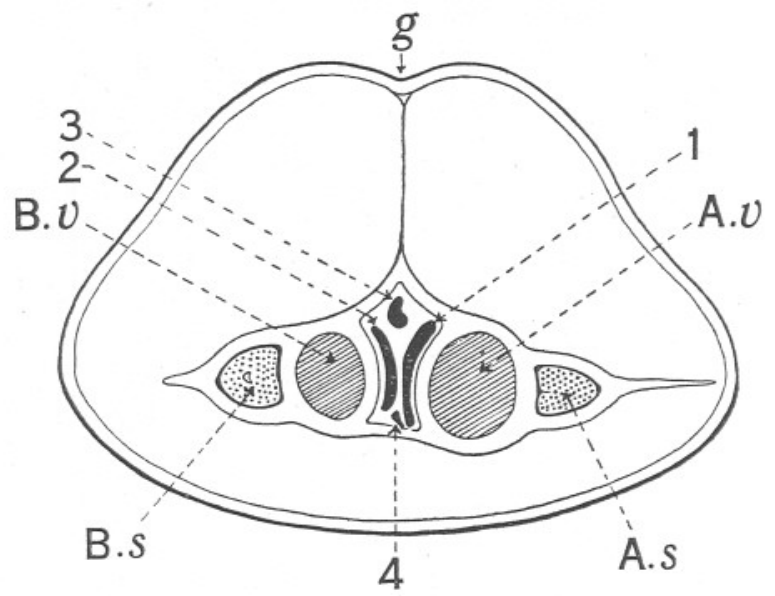

TExT Fig. 8.--Hand-section of Double-monster across tail-end behind pelvics. Section cut in direction $\mathrm{S}-\mathrm{S}$ indicated in Plate V.
A. v. centrum of A.
B. v. centrum of B.
g. external groove.
A. s. spinal cord of A.
B. s. spinal cord of B.
$1,2,3$, and 4 . Blood-vessels in united hæmal arches.

passes into a median intestine (I) with a spiral valve of the usual character. Near its front end the intestine receives on either side a two-limbed stomach. The larger of these two stomachs (A. sT.) can be traced to the œsophagus of the member $\mathrm{A}$, and is supplied with a normal pancreas (A. P.) and spleen (A. sp.). The smaller stomach (B. st.) leads to the œsophagus of the member B, but, unlike its fellow, is without either pancreas or spleen. At the front end of the intestine there is communication (Fig. 7, Y) with the internal yolk-sac. The latter is a bi-lobed organ, communicating on the one hand, as stated, by a median opening to the intestine at $\mathrm{Y}$, and, on the other, to the external yolk-sac by a single channel in the yolk-stalk. Both members of the monster have 
a bi-lobed liver, but that of member B is much the smaller and very unequally lobed.

\section{Hand Section across the Tail-region.}

A hand section across the tail a short way behind the pelvic fins is shown diagrammatically in Text-Fig. 8 . It is seen that members $A$ and $B$ retain their identity so far as the centrum and spinal cord are concerned, but that there is fusion of the hæmal arches, enclosing the blood-vessels of both. In the description of the external features of the specimen, reference was made to the small fleshy lobe (c) at the root of the single normal heterocercal tail, and the suggestion was made that (c) may represent the tail of $B$. Sections cut posterior to the one just described lend support to this view in that the identity of $B$ can be traced backwards to (c).

The monster would thus appear to be the union of two embryos, of which one (A) is dominant. In a letter to Nature on May 25th, 1929, von Bonde and Marchand ('), p. 795) describe a somewhat similar union in Squalus fernandinus. Their specimen differs in having a more advanced duplication of the tail, while the nostrils of both members appear normal. The section across the tail region shown in their Figure 2 also differs from that represented in Text-Fig. 8 of this paper in several respects. In the section of $S$. fernandinus the blood-vessels are shown separated from the "lateral arch" facing the external groove by a thick line, presumably indicative of cartilage. But in Acanthias vulgaris a blood-vessel (Text-Fig. 8,3 ) is seen to occupy this lateral arch, there being no cartilaginous crosspiece separating a hæmal arch from a "lateral arch." At the time of writing their letter von Bonde and Marchand had not dissected their specimen for an examination of the internal organs. It will be interesting to know, when they have done so, how far their specimen agrees with the present one in the characters of the alimentary canal.

\section{LITERATURE CITED.}

1. Bashford Dean. A Bibliography of Fishes. Vol. III. New York, 1923.

2. Gemmil, J. F. The Teratology of Fishes. Glasgow, 1912.

3. Gesner, C. Historia animalium. Part IIII. Tiguri, 1556.

4. Howes, G. B. On Synostoses and Curvature of the Spine in Fishes, with especial reference to the Sole. Proc. Zool. Soc., London, 1894, p. 95 . 
5. Johnstone, J. Ray showing Arrested Development of the Pectoral Fins. Report for 1905 on the Lancashire Sea-Fisheries Laboratory, Liverpool, 1906, p. 188.

6. Storrow, B. A case of Spinal Curvature in a Codling. Northumberland Sea Fisheries Report for 1909, pp. 37-39.

7. von Bonde, C., And Marchand, J. A Case of "Siamese Twins" in the Spiny Dogfish (Squalus fernandinus). Nature, Vol. 123, 1929, p. 795 .

8. Williamson, H. C. Abnormal Skate (Raia circularis and Raia clavata). 28th Report, Fishery Board for Scotland (1911), Part III, p. 64 .

\section{EXPLANATION OF PLATES.}

\section{PLATE I.}

Sagittal Section of Head of Malformed Cod.

d. original left-half of lower jaw.

t. tongue lying in extension of mouth-cavity.

h. heart.

\section{PLATE II.}

Fan-tailed Pilchard.

Left: From X-ray photograph by Institute of Anatomy, University College, London.

Lower right: Tail of Fan-tailed Pilchard.

Upper right: Tail of normal Pilchard of approximately same length.

\section{PLATE III.}

Abnormal specimen of Pleuronectes microcephalus Donov. From X-ray photograph by Institute of Anatomy, University College, London.

PLATE IV.

6 A. Abnormal Raia microcellata Mont.

6 B. Abnormal Raia clavata L.

\section{PLATE V.}

Double-monster of Acanthias vulgaris Risso. (Photo, C. H. Gill.)
A. Larger member.
c. Rudimentary tail of $\mathrm{B}$.
B. Smaller member.
n. Abnormal nostrils of $B$.

y. Severed end of yolk-stalk. 
Journ. Mar. Biol. Assoc. XVII.-1.

PLATE I.

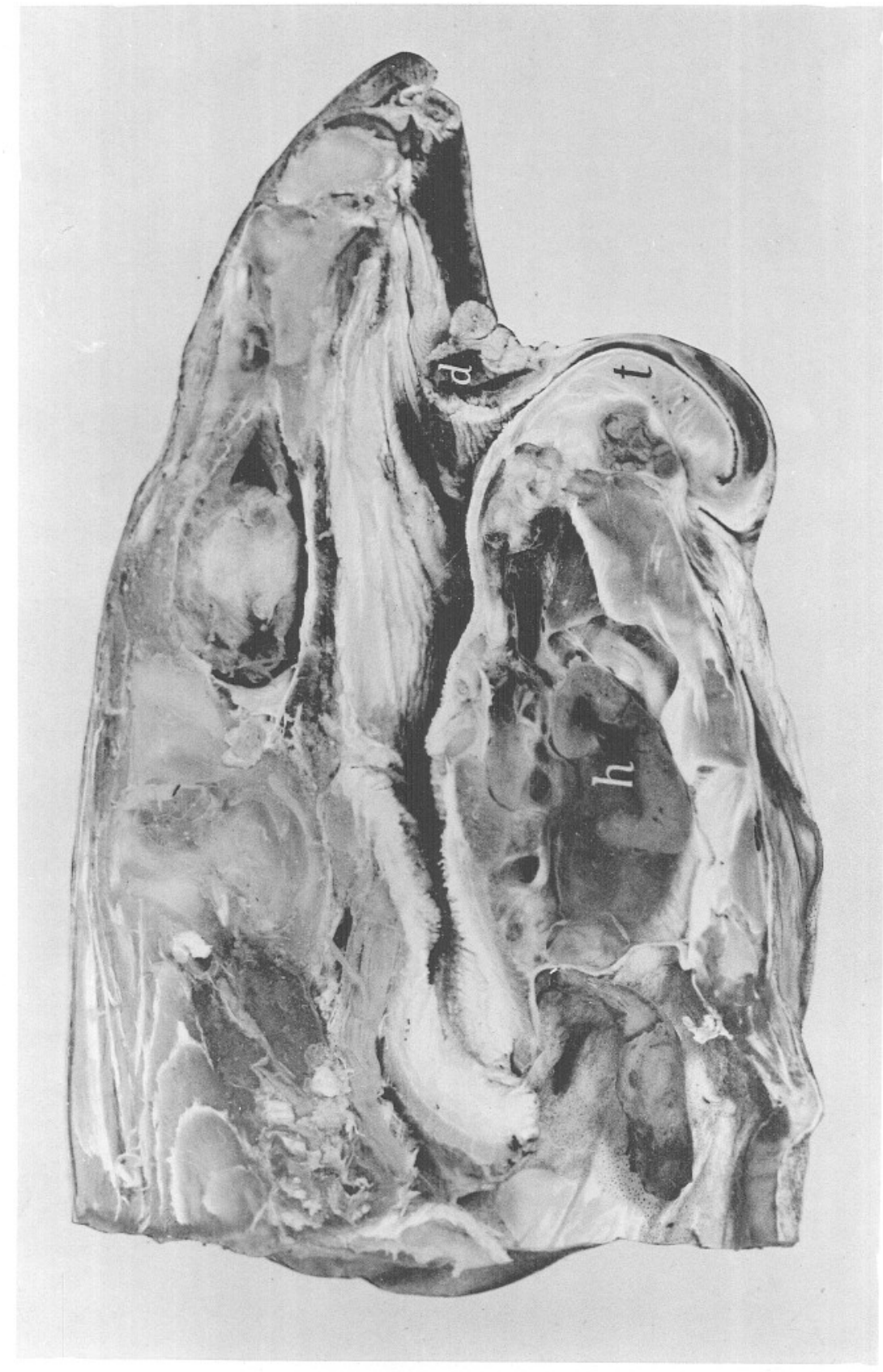



Journ. Mar. Biol. Assoc. XVII.-1.

PLATE II.

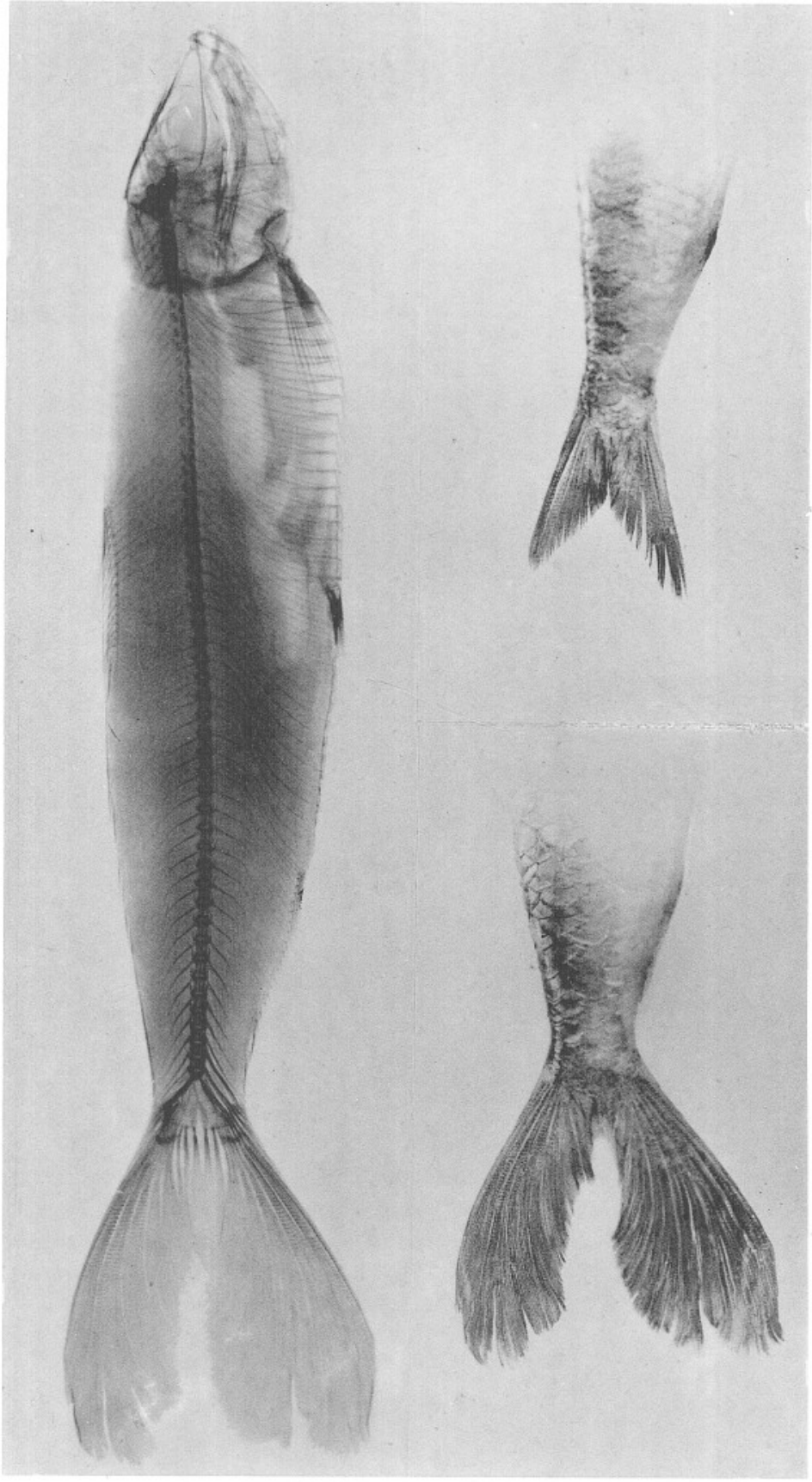



PLATE III.

Journ. Mar. Biol. Assoc. XVII.-1.

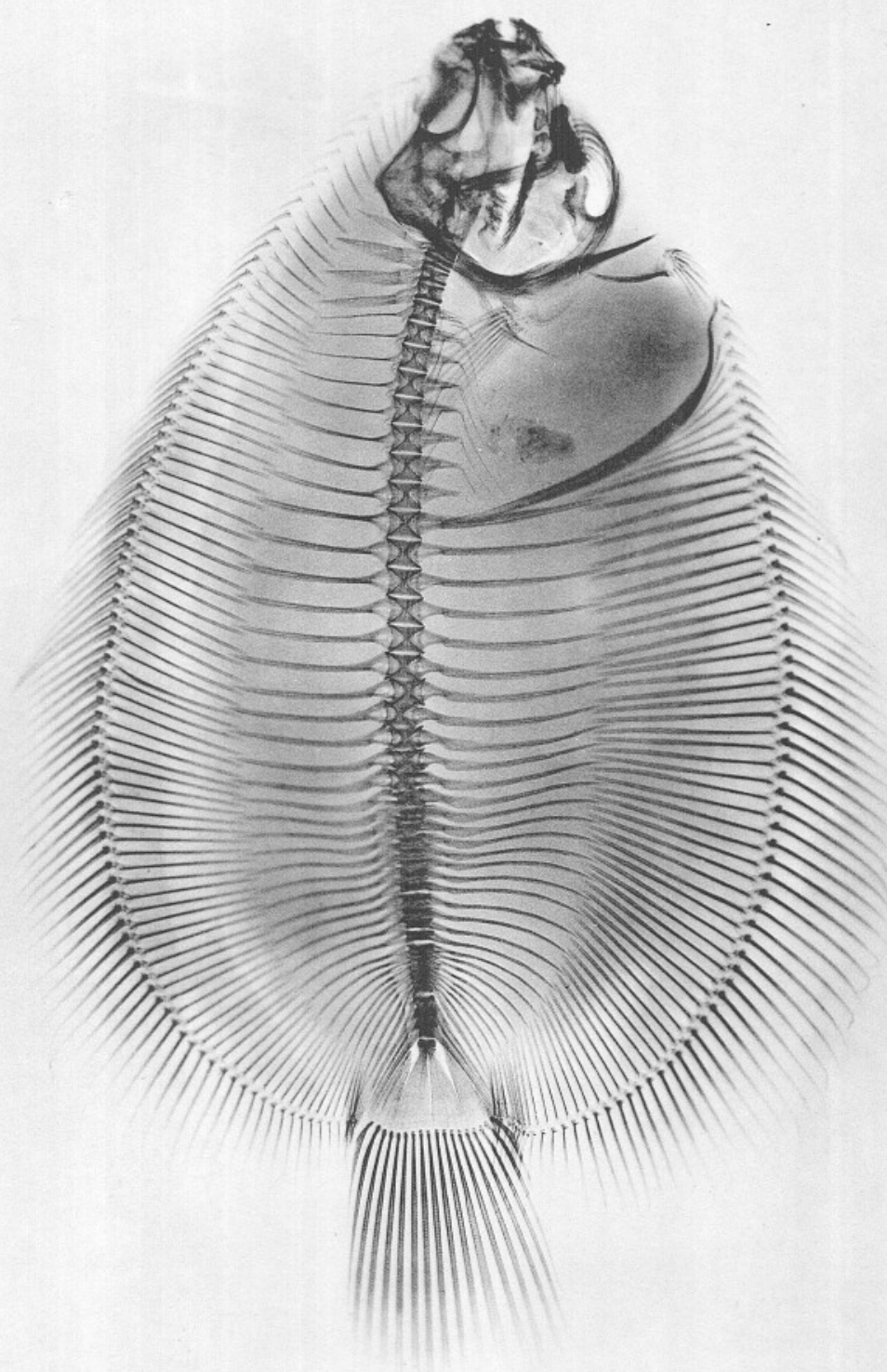




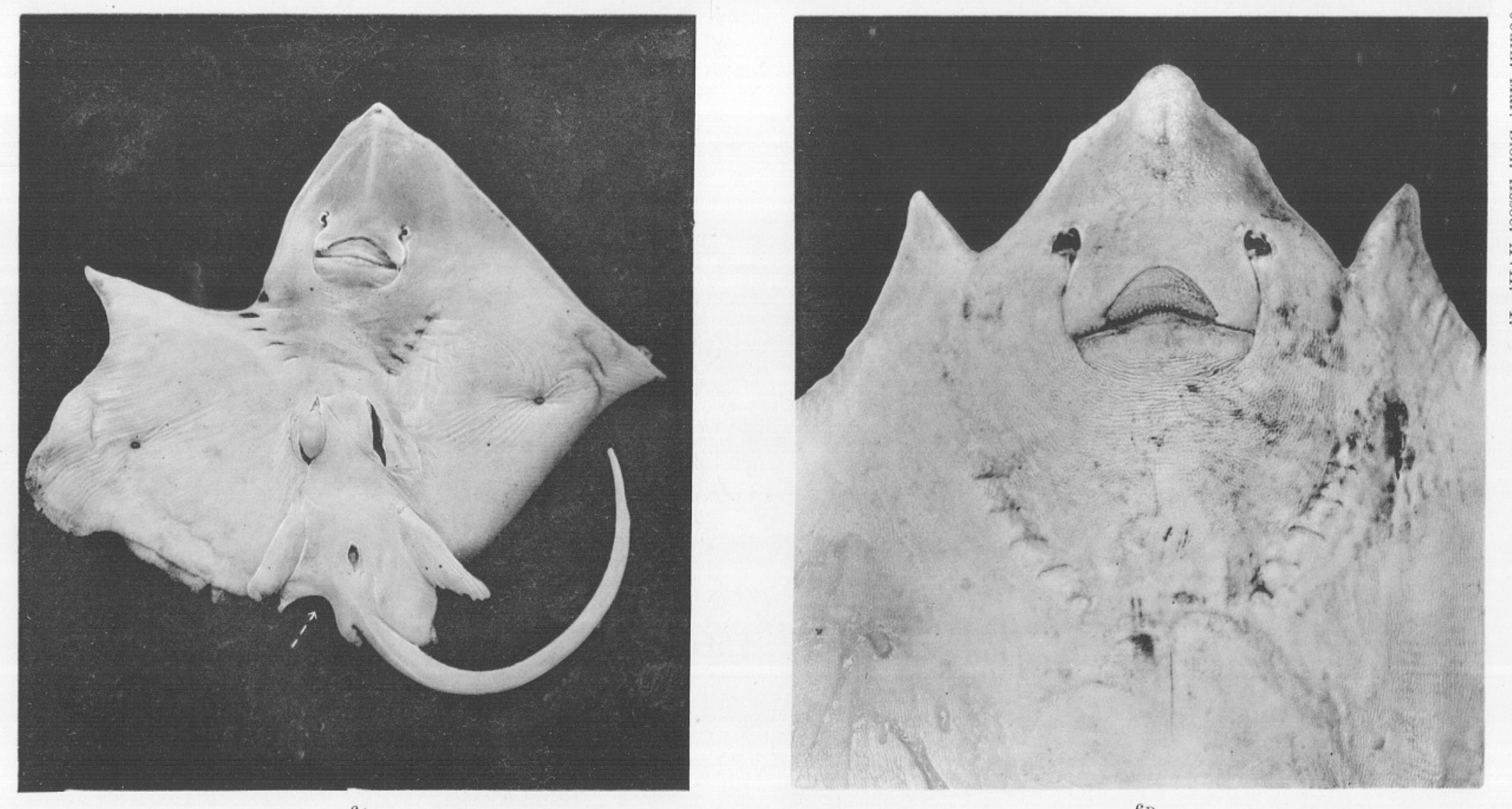

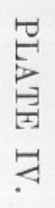



Journ. Mar. Biol. Assoc. XVII.-1.
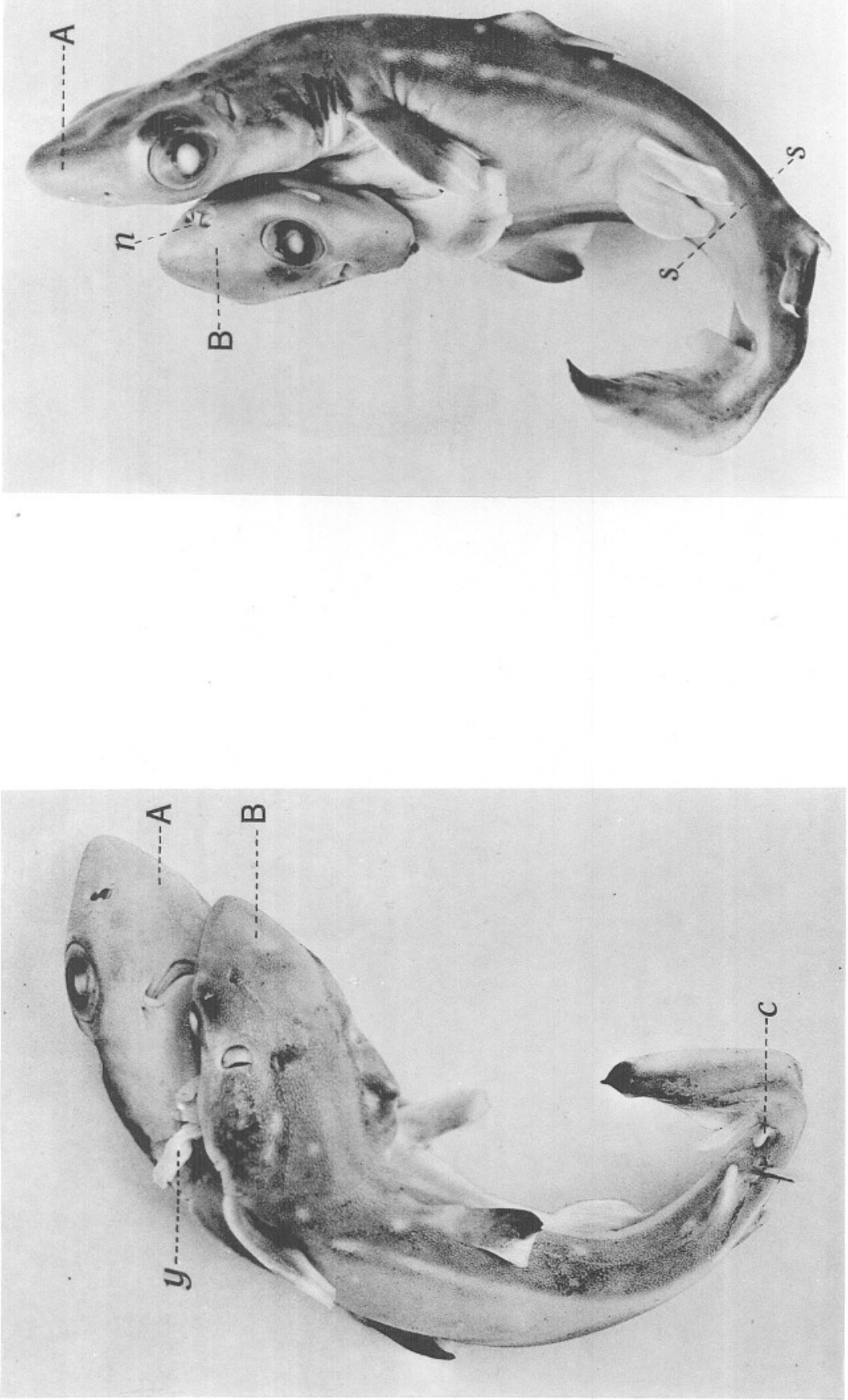
